\title{
Power abilities: recognition of the level of development in girls aged 12-14 years
}

Ivashchenko O.V. ${ }^{1 \mathrm{ABCDE}}$, Khudolii O.M. ${ }^{1 \mathrm{ABCDE}}$, Iermakov S.S. ${ }^{2 \mathrm{ABCDE}}$, Veremeenko V.Yu. ${ }^{1 \mathrm{ABCDE}}$, Lopatiev A.O. ${ }^{3 \mathrm{ABCDE}}$

${ }^{1}$ Faculty of Physical Education and Sports, H.S. Skovoroda Kharkiv National Pedagogical University, Ukraine

${ }^{2}$ Department of Tourism and Recreation, Gdansk University of Physical Education and Sport, Poland

${ }^{3}$ Department of Shooting and Technical Sports, Lviv State University of Physical Culture, Ukraine

Authors' Contribution: A - Study design; B - Data collection; C - Statistical analysis; D - Manuscript Preparation; E - Funds Collection

\begin{tabular}{|c|c|}
\hline \multicolumn{2}{|l|}{ Abstract } \\
\hline Purpose: & $\begin{array}{l}\text { The purpose of the study is to determine the possibility of recognizing the state of power abilities development } \\
\text { in girls aged 12-14 years based on the methodology of multidimensional statistics. }\end{array}$ \\
\hline Material: & $\begin{array}{l}\text { The study involved girls: } 12(n=21), 13(n=20), 14(n=19) \text { years old. The study used the following methods: } \\
\text { analysis and collation of scientific and methodological literature, general scientific methods of theoretical } \\
\text { level, such as analogy, analysis, synthesis, abstraction, induction, as well as general scientific methods of } \\
\text { empirical level: observation, testing, experiment. The testing program included well-known tests. }\end{array}$ \\
\hline Results: & $\begin{array}{l}\text { In the recognition of the state of power abilities development in girls aged } 12-14 \text { years the most important } \\
\text { are the results in tests: Pull-Up / Chin Up Test (Rope Climbing), quantity of times (0.877); Squats Test (two legs), } \\
\text { quantity of times ( } 0.723) \text {; Single Leg Squat (SLS) Test - left leg, quantity of times (-0.567); Pull-Up / Chin Up } \\
\text { Test (low crossbar), quantity of times (-0.467). These tests describe the level of muscle strength development } \\
\text { of the shoulder girdle and legs. In the recognition of the state of power abilities development in girls aged } \\
13-14 \text { years the most important are the results in tests: Single Leg Squat (SLS) Test - left leg, quantity of times } \\
(-0.825) \text {; Single Leg Squat (SLS) Test - right leg, quantity of times (0.735); Single Leg Squat (Pistol) - left leg } \\
\text { (0.672); Hand tapping test, sec. (0.682). These tests describe the level of development of relative and static } \\
\text { strength of the legs. }\end{array}$ \\
\hline Conclusions: & $\begin{array}{l}\text { Discriminant analysis allowed to determine informative indicators for cross-control of the development of } \\
\text { power abilities in girls aged 12-14 years; answer the question of how significantly the state of development } \\
\text { of power abilities in girls of 12, } 13 \text { and } 14 \text { years is different; which motor tests most significantly affect the } \\
\text { differentiation of classes; which class the object belongs to (based on the values of discriminant variables). In } \\
\text { order to recognize the level of development of power abilities in girls aged } 12-14 \text { years, it is necessary to be } \\
\text { guided by the indicators of relative and static strength and strength endurance; at girls of } 13 \text { and } 14 \text { years - } \\
\text { strength endurance. }\end{array}$ \\
\hline & criminant analysis, pattern recognition, girls 12-14 years old \\
\hline
\end{tabular}

\section{Introduction}

Motor activity and its impact on the health of the population is one of the problems actively studied in the field of physical education [1,2]. Physical education of schoolchildren is aimed at optimizing the physical development of the child [3, 4], improving the process of development of motor abilities [5, 6], strengthening and health [7]. Power abilities relate to the basic, their level of development affects the effectiveness of teaching physical exercises of schoolchildren [5, 8].

Based on numerous studies, conclusions are the following:

- on the effectiveness of complex development of strength, vigor, coordination, endurance and flexibility in children [9, 10];

- on the influence of the level of development of force on the process of learning the physical exercises of schoolchildren [5, 11];

- on the effectiveness of the use of tools and methods of training in the development of power capabilities [12, 13].

In previously published works, attention was focused

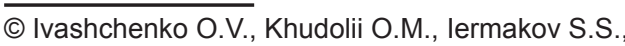

Veremeenko V.Yu., Lopatiev A.O., 2018

doi:10.15561/18189172.2018.0305 on the study of the relationship of indicators of the level of schoolchildren motor abilities development [5, 14], as well as on the definition of their structure $[15,16]$.

Multidimensional methods of mathematical statistics such as factor and discriminant analysis [5, 17] are effective for studying the structure of motor readiness of schoolchildren. The use of factor analysis allowed to establish the structure of development of motor abilities of schoolchildren [18]. However, in available literature there is not enough data on the peculiarities of the dynamics of the development of power abilities in high school students.

Thus, the study of the peculiarities of the dynamics of power abilities development on the basis of recognition of the state of their development in girls of middle classes is relevant.

The purpose of the study is to determine the possibility of recognizing the state of development of power abilities in girls aged 12-14 years based on the methodology of multidimensional statistics.

\section{Materials and methods}

Study participants. The study involved girls: 12 (n $=21), 13(\mathrm{n}=20), 14(\mathrm{n}=19)$ years old. 
The study protocol was approved by the Ethical Committee of H. S. Skovoroda Kharkiv National Pedagogical University. In addition, the children and their parents or legal guardians were fully informed about all the features of the study, and a signed informed-consent document was obtained from all the parents.

Study organization. The study used the following methods: analysis and collation of scientific and methodological literature, general scientific methods of theoretical level, such as analogy, analysis, synthesis, abstraction, induction, as well as general scientific methods of empirical level: observation, testing, experiment.

Testing procedure. The testing program included wellknown tests [5, 9, 19]. To evaluate motor preparedness, the study recorded the results of motor tests:

- Test 1. Pull-Up / Chin Up Test (low crossbar), quantity of times;

- $\quad$ Test 2. Bent Arm Hang Test (two hands), sec.;

- $\quad$ Test 3. Pull-Up / Chin Up Test (Rope Climbing), quantity of times;

- $\quad$ Test 4. Cadence Push-Up Test, quantity of times;

- Test 5. The subject lies in prone position, arms bent at the elbow 90 degrees - hold position in seconds;

- $\quad$ Test 6. Pull Up Bar- Straight Leg Hanging Leg Raises, quantity of times;

- $\quad$ Test 7. Hanging Leg Raises, sec.;

- $\quad$ Test 8. Trunk Lift Test, quantity of times;

- Test 9. Squats Test (two legs), quantity of times;

- $\quad$ Test 10. Single Leg Squat (SLS) Test - right leg, quantity of times;

- $\quad$ Test 11. Single Leg Squat (SLS) Test - left leg, quantity of times;

- Test 12. Single Leg Squat (Pistol) - right leg;

- $\quad$ Test 13. Single Leg Squat (Pistol) - left leg;

- $\quad$ Test 14. Handgrip Strength Test, kg;

- $\quad$ Test 15. Standing Long Jump Test (Broad Jump), $\mathrm{cm}$;

- $\quad$ Test 16. Eurofit Sit Up Test (for 30 sec.), quantity of times;

- $\quad$ Test 17. 4x9 m shuttle test, sec.;

- Test 18. Hand tapping test, sec.;

- $\quad$ Test 19. Seated Forward Bend, cm;

- Test 20. Flamingo Balance test - single leg balance test.
Statistical analysis.

In discriminant analysis we formed prognostic model of belonging to group. This model builds discriminant function (or if the quantity of groups is more than two - a set of discriminant functions) in the form of linear combination of variables-predictors that ensures the best groups' division. These functions are built by a set of observations, for which their belonging to groups is known. Further, these functions can be used for new observations with known values of variables- predictors and unknown belonging to group.

For every variable we calculated the following: mean values, standard deviations, single - factorial dispersion analysis for every variable (Box's $M$ test, in-group correlation matrix, in-group covariance matrix, covariance matrixes for separate groups, general covariance matrix). For every canonic discriminant function we calculated: eigenvalue, dispersion percentage, canonic correlation, Wilks' Lambda, Chi-square. For every step we calculated: priory probabilities, Fisher function's coefficients, non-standardized coefficients of function, Wilks' Lambda for every canonic function

\section{Results}

The tables show the results of discriminant analysis, which allow to recognize the state of development of power abilities in girls of 12-14 years old.

The first canonical function explains the variation of the results by $87.8 \%$, the second - by $12.2 \%$, which indicates their informativity (see Table 1). The coefficients of canonical correlation $(r=0.892 ; r=0.592)$ indicate the prognosticity of the first and second functions.

Table 2 shows the analysis of canonical functions. The first line contains the value $\lambda=0,133(p=0,001)$ for the entire set of canonical functions, the second line is the data after the first function is excluded $(\lambda=0,650$; $p=0,087)$. The first and second functions have a high discriminative ability and meaning in the interpretation of the general population.

Table 3 shows the normalized coefficients of the canonical discriminant function, which allow us to determine the ratio of the contribution of variables to the result of the function. The greatest contribution to the first canonical function is the variables No. $3,9,11,1$ : the

Table 1. Summary of Canonical Discriminant Functions. Eigenvalues. Girls of $12-14$ years

\begin{tabular}{lllll}
\hline Function & Eigenvalue & \% of Variance & Cumulative \% & Canonical Correlation \\
\hline 1 & $3,884^{a}$ & 87,8 & 87,8 &, 892 \\
2 &, $539^{a}$ & 12,2 & 100,0 &, 592 \\
\hline
\end{tabular}

Table 2. Canonical discriminatory functions. Wilks' Lambda. Girls of $12-14$ years

\begin{tabular}{lllll}
\hline Test of Function(s) & Wilks' Lambda & Chi-square & df & Sig. \\
\hline 1 through 2 &, 133 & 130,096 & 40 &, 000 \\
2 &, 650 & 27,796 & 19 &, 087 \\
\hline
\end{tabular}


larger the values of these variables, the greater the value of the function. The greatest contribution to the second canonical function is the variables No. 11, 10, 13, 18: the larger the values of these variables, the greater the value of the function.

In identifying the state of development of power abilities in girls aged 12-14 years old the most important are the results in the tests: № $3(0,877)$, № $9(0,723)$, № $11(-0,567)$, №1 $(-0,467)$. These tests describe the level of muscle strength development of the shoulder girdle and legs.

In recognition of the state of development of power abilities in girls aged 13-14 years old, the most important are the results in the tests: No. $11(-0,825)$, No. $10(0,735)$, No. $13(0,672)$, No. $18(0,682)$. These tests describe the level of development of relative and static strength of the legs.

Table 4 shows the structural coefficients of the first and second canonical discriminant functions, which are coefficients of the correlation of variables with a function. Thus, the first canonical discriminant function is most closely connected with the results of tests No. 9, 5, 3, 8, 6, 14: hence, the significant difference between girls of 12 , 13 , and 14 years is observed in the level of development of relative, static strength and strength endurance.

The structural coefficients of the second canonical discriminant function indicate that the function is most closely related to the variables No. 18, 16: hence, the significant difference between girls of 13 and 14 years is observed in the level of development of force and endurance of muscles of the abdominal press.

Table 5 shows the results of classification of groups, $89.6 \%$ of the output grouped observations are categorized correctly. Thus, a canonical discriminatory function can be used to recognize the state of development of power abilities in girls of 12-14 years old.

\section{Discussion}

The results show that discriminant analysis allows to recognize the state of development of power abilities in girls aged 12-14 years on the results of testing and supplement data on the use of discriminant function in the classification of schoolchildren by motor activity [20, 21]. Also, works of Geoffrey D. et al. [22], Ivashchenko et al. [23] show a high discriminant and predictive ability of the functions obtained in assessing the strength of girls aged 12-14 years old.

It is confirmed that multidimensional methods of mathematical statistics such as factor and discriminant analysis $[5,17]$ are effective for studying the strength training structure of girls aged 12-14 years old. It is added that the use in the analysis of the structural coefficients

Table 3. Standardized Canonical Discriminant Function Coefficients. Girls aged 12-14 years old

\begin{tabular}{llll}
\hline № & Test & Function & \\
\hline 1 & Pull-Up / Chin Up Test (low crossbar), quantity of times & $\mathbf{1}$ & $\mathbf{2}$ \\
2 & Bent Arm Hang Test (two hands), sec. &,- 467 &,- 132 \\
3 & Pull-Up / Chin Up Test (Rope Climbing), quantity of times &, 064 &, 157 \\
4 & Cadence Push-Up Test, quantity of times &, 877 &, 291 \\
& The subject lies in prone position, arms bent at the elbow 90 degrees - hold &, 366 &, 176 \\
5 & position in seconds &, 220 &, 113 \\
6 & Pull Up Bar- Straight Leg Hanging Leg Raises, quantity of times &, 185 &, 398 \\
7 & Hanging Leg Raises, sec. &, 358 &,- 033 \\
8 & Trunk Lift Test, quantity of times &, 290 &,- 421 \\
9 & Squats Test (two legs), quantity of times &, 723 &, 012 \\
10 & Single Leg Squat (SLS) Test - right leg, quantity of times &,- 101 &, 735 \\
11 & Single Leg Squat (SLS) Test - left leg, quantity of times &,- 567 &,- 825 \\
12 & Single Leg Squat (Pistol) - right leg &, 140 &,- 536 \\
13 & Single Leg Squat (Pistol) - left leg &,- 046 &, 672 \\
14 & Handgrip Strength Test, kg &, 295 &,- 089 \\
15 & Standing Long Jump Test (Broad Jump), cm &,- 202 &,- 404 \\
16 & Eurofit Sit Up Test (for 30 sec.), quantity of times &,- 154 &, 625 \\
17 & 4x9 m shuttle test, sec. &, 257 &,- 205 \\
18 & Hand tapping test, sec. &,- 373 &, 682 \\
19 & Seated Forward Bend, cm &, 305 &, 323 \\
20 & Flamingo Balance test - single leg balance test &, 154 &, 168 \\
\hline & & &
\end{tabular}


of the discriminant function allows to determine the structure of the development of power abilities and their interrelation with endurance at girls aged $12-14$ years [ 18 , 23].

For the practical application of the results of discriminant analysis, the coefficients of the canonical discriminant function are used (see Table 6). The probability that some case belongs to the predicted group is calculated based on the substitution of the discriminant function of the values of the set of variables that correspond to the case. Comparison of the obtained results with the magnitude of centroids makes it possible to determine the group to which the result refers (Table 7). The above data supplements the results of study of the

Table 4. Structure Matrix. Girls aged 12-14 years old

\begin{tabular}{|c|c|c|c|}
\hline \multirow{2}{*}{ № } & \multirow{2}{*}{ Test } & \multicolumn{2}{|c|}{ Function } \\
\hline & & 1 & 2 \\
\hline 9 & Squats Test (two legs), quantity of times & $458^{*}$ & 051 \\
\hline 5 & $\begin{array}{l}\text { The subject lies in prone position, arms bent at the elbow } 90 \text { degrees - hold } \\
\text { position in seconds }\end{array}$ &, $306^{*}$ & ,006 \\
\hline 3 & Pull-Up / Chin Up Test (Rope Climbing), quantity of times &, $296^{*}$ & ,086 \\
\hline 8 & Trunk Lift Test, quantity of times &, $279^{*}$ &,- 253 \\
\hline 6 & Pull Up Bar- Straight Leg Hanging Leg Raises, quantity of times &, $238^{*}$ & 130 \\
\hline 14 & Handgrip Strength Test, kg &, $237^{*}$ &,- 052 \\
\hline 19 & $\begin{array}{l}\text { Raising of a straight legs to the head from the position of lying on a bench } \\
\text { angularly } 45 \text { and holding the wall bar, times }{ }^{\text {b }}\end{array}$ &, $210^{*}$ &,- 020 \\
\hline 7 & Hanging Leg Raises, sec. & $205^{*}$ & 094 \\
\hline 13 & Single Leg Squat (Pistol) - left leg & $149^{*}$ & 112 \\
\hline 2 & Bent Arm Hang Test (two hands), sec. & $146^{*}$ & 014 \\
\hline 10 & Single Leg Squat (SLS) Test - right leg, quantity of times & $142^{*}$ & ,000 \\
\hline 12 & Single Leg Squat (Pistol) - right leg & $139^{*}$ & 064 \\
\hline 1 & Pull-Up / Chin Up Test (low crossbar), quantity of times & $137^{*}$ & 132 \\
\hline 11 & Single Leg Squat (SLS) Test - left leg, quantity of times & ,099* &,- 046 \\
\hline 18 & Hand tapping test, sec. &,- 352 &, $411^{*}$ \\
\hline 16 & Eurofit Sit Up Test (for $30 \mathrm{sec}$. ), quantity of times & 124 & ,391* \\
\hline 20 & Flamingo Balance test - single leg balance test &, $058^{*}$ & ,200 \\
\hline 19 & Seated Forward Bend, cm & $119^{*}$ & 199 \\
\hline 4 & Cadence Push-Up Test, quantity of times &, $114^{*}$ & 179 \\
\hline 15 & Standing Long Jump Test (Broad Jump), cm & $078^{*}$ &,- 175 \\
\hline 17 & $4 \times 9 \mathrm{~m}$ shuttle test, sec. &, $013^{*}$ &,- 123 \\
\hline
\end{tabular}

*. Largest absolute correlation between each variable and any discriminant function

b. This variable not used in the analysis.

Table 5. Classification Results ${ }^{a}$. Girls aged 12-14 years old

\begin{tabular}{|c|c|c|c|c|c|c|}
\hline \multirow{2}{*}{ Scale } & & \multirow{2}{*}{ Age (years) } & \multicolumn{3}{|c|}{ Predicted Group Membership } & \multirow{2}{*}{ Total } \\
\hline & & & 12,00 & 13,00 & 14,00 & \\
\hline \multirow{6}{*}{ Original } & \multirow{4}{*}{ Count } & 12,00 & 20 & 0 & 0 & 20 \\
\hline & & 13,00 & 0 & 21 & 6 & 27 \\
\hline & & 14,00 & 0 & 2 & 28 & 30 \\
\hline & & 12,00 & 100,0 & 0 & 0 & 100,0 \\
\hline & \multirow[t]{2}{*}{$\%$} & 13,00 & 0 & 77,8 & 22,2 & 100,0 \\
\hline & & 14,00 & 0 & 6,7 & 93,3 & 100,0 \\
\hline
\end{tabular}

\footnotetext{
a. $89,6 \%$ of original grouped cases correctly classified.
} 
Table 6. Canonical Discriminant Function Coefficients (Unstandardized coefficients). Girls aged 12-14 years old

\begin{tabular}{|c|c|c|c|}
\hline \multirow{2}{*}{ № } & \multirow{2}{*}{ Test } & \multicolumn{2}{|l|}{ Function } \\
\hline & & 1 & 2 \\
\hline 1 & Pull-Up / Chin Up Test (low crossbar), quantity of times &,- 193 &,- 054 \\
\hline 2 & Bent Arm Hang Test (two hands), sec. & ,081 & 198 \\
\hline 3 & Pull-Up / Chin Up Test (Rope Climbing), quantity of times & ,363 & 121 \\
\hline 4 & Cadence Push-Up Test, quantity of times & 108 & ,052 \\
\hline 5 & $\begin{array}{l}\text { The subject lies in prone position, arms bent at the elbow } 90 \text { degrees - hold } \\
\text { position in seconds }\end{array}$ & ,082 & ,042 \\
\hline 6 & Pull Up Bar- Straight Leg Hanging Leg Raises, quantity of times & 120 & ,258 \\
\hline 7 & Hanging Leg Raises, sec. & ,326 &,- 030 \\
\hline 8 & Trunk Lift Test, quantity of times & ,058 &,- 084 \\
\hline 9 & Squats Test (two legs), quantity of times & 163 & ,003 \\
\hline 10 & Single Leg Squat (SLS) Test - right leg, quantity of times &,- 107 & ,782 \\
\hline 11 & Single Leg Squat (SLS) Test - left leg, quantity of times &,- 615 &,- 895 \\
\hline 12 & Single Leg Squat (Pistol) - right leg &, 122 &,- 467 \\
\hline 13 & Single Leg Squat (Pistol) - left leg &,- 044 &, 642 \\
\hline 14 & Handgrip Strength Test, kg & ,173 &,- 052 \\
\hline 15 & Standing Long Jump Test (Broad Jump), cm & $-1,241$ & $-2,481$ \\
\hline 16 & Eurofit Sit Up Test (for $30 \mathrm{sec}$. ), quantity of times &,- 039 & ,158 \\
\hline 17 & $4 \times 9$ m shuttle test, sec. & ,426 &,- 339 \\
\hline 18 & Hand tapping test, sec. &,- 454 & ,830 \\
\hline 19 & Seated Forward Bend, cm & 129 & 137 \\
\hline \multirow[t]{2}{*}{20} & Flamingo Balance test - single leg balance test & 079 & ,087 \\
\hline & (Constant) & $-10,210$ & $-9,678$ \\
\hline
\end{tabular}

Table 7. Functions at Group Centroids. Girls aged 12-14 years old

\begin{tabular}{lll}
\hline Group & Function & $\mathbf{2}$ \\
\hline 12,00 & $\mathbf{1}$ &,- 451 \\
13,00 & $-3,029$ &, 977 \\
14,00 &, 184 &,- 579 \\
\hline
\end{tabular}

peculiarities of schoolchildren motor readiness [15, 24, 25].

\section{Conclusions}

Discriminant analysis allowed to determine informative indicators for cross-control of the development of power abilities in girls aged 12-14 years old; answer the question of how significantly the state of development of power abilities in girls of 12, 13 and 14 years is different; which motor tests most significantly affect the differentiation of classes; to which class the object belongs, based on the values of discriminant variables.

In order to recognize the level of development of power abilities in girls aged 12-14 years old, it is necessary to be guided by the indicators of relative and static strength and strength endurance; at girls of 13 and 14 years - strength endurance.

\section{Acknowledgment}

The research was carried out according to the theme 13.04 "Modelling of the learning process and development of motor abilities in children and adolescents" (20132014) (state registration number 0113U002102).

\section{Conflict of Interest}

The authors state that there is no conflict of interest. 


\section{References}

1. Bădicu G, Balint L. The influence of leisure sports activities on social health in adults. SpringerPlus, 2016; 5(1): 1647. doi:10.1186/s40064-016-3296-9

2. Bădicu G. Physical Activity and Health-Related Quality of Life in Adults from Braşov, Romania. Education Sciences, 2018; 8(2). doi:10.3390/educsci8020052

3. Balsevich VK. Ontokinesiology of man. Moscow: Theory and practice of physical culture; 2000. (in Russian)

4. Novak D, Podnar H, Emeljanovas A, Marttinen R. Comparison of Fitness Levels between Croatian and Lithuanian Students. Montenegrin Journal of Sports Science and Medicine, 2015; 4(1): 5-11.

5. Ivashchenko OV. Modelling of physical education students. Kharkiv: OVS; 2016. (in Ukrainian)

6. Emeljanovas A, Mieziene B, Putriute V. The Relationship Between Physical Activity and Content of the Physical Education Classes in 11-12 Years Old Lithuanian Schoolchildren. The Pilot Study. Croatian Journal of Education-Hrvatski Casopis Za Odgoj I Obrazovanje, 2015; 17(1): 93-120.

7. Krutsevych TYu, Bezverkhnia HV. Recreation in the physical culture of different population groups: teaching. manual. Kiev: Olympic Literature; 2010. (in Ukrainian)

8. Ilyin EP. Psychomotor organization of man: training. for universities. St. Petersburg: Peter; 2003. (in Russian)

9. Liakh VI. Driving abilities of schoolchildren: Fundamentals of theory and methods of development. Moscow: TerraSport; 2000.

10.Khudolii OM. General Fundamentals of Theory and Methodology of Physical Education. Kharkiv: OVS; 2008. (in Ukrainian)

11.Ivashchenko O, Prykhodko V, Cieslicka M. (2018). Movement Coordination: Factor Structure of Development in 5th-7th Grade Girls. Teoriâ Ta Metodika Fìzičnogo Vihovannâ, 2018; 18(1): 38-49. doi:10.17309/tmfv.2018.1.05

12.Liu C, Chen CS, Ho WH, Fule RJ, Chung PH, Shiang TY. The Effects of Passive Leg Press Training on Jumping Performance, Speed, and Muscle Power. Journal of Strength and Conditioning Research, 2013; 27(6): 1479-86.

13.Cieślicka M, Ivashchenko O. Discriminant analysis method to determine the power of the boys 11-12 year. Journal of Education, Health and Sport, 2016; 6(10): 7)21-9.

14.Khudolii OM, Ivashchenko OV. Simulation of the learning process and development of motor abilities in children and adolescents. Kharkiv: OVS; 2014. (in Ukrainian)
15.Ivashchenko O, Khudolii O, Iermakov S, Lochbaum M, Cieślicka M, Zukow W, Nosko M, Yermakova T. Methodological approaches to pedagogical control of the functional and motor fitness of the girls from 7-9 grades. Journal of Physical Education and Sport, 2017; 17(1): 254261.

16.Khudolii OM, Iermakov SS, Prusik K. Classification of motor fitness of 7-9 years old boys. Journal of Physical Education and Sport, 2015; 15(2): 245-253. doi:10.7752/ jpes.2015.02038

17.Lopatiev A, Ivashchenko O, Khudolii O, Pjanylo Y, Chernenko S, Yermakova T. Systemic approach and mathematical modeling in physical education and sports. Journal of Physical Education and Sport, 2017; 17 (1):146155.

18.Ivashchenko O. Methodological Approaches to Pedagogical Control of Motor Readiness of Girls Aged 6-10. Teorîa Ta Metodika Fizičnogo Vihovannâ, 2017; 17(3): 126-138. doi:10.17309/tmfv.2017.3.1197

19.Serhiienko LP. Testing of motor abilities of schoolchildren. Kiev: Olympic Literature; 2001. (in Ukrainian)

20.Gert-Jan de Bruijn, Benjamin Gardner. Active Commuting and Habit Strength: An Interactive and Discriminant Analyses Approach. American Journal of Health Promotion, 2011; 25(3): e27-e36. doi:10.4278/ajhp.090521-QUAN-170

21.Lulzim I. Discriminant analysis of morphologic and motor parameters of athlete and non athlete girl pupils of primary school on age 14 to 15 years. RIK, 2013; 40(2): 185-190.

22.Geoffrey D Broadhead, Gabie E Church. Discriminant Analysis of Gross and Fine Motor Proficiency Data. Perceptual and Motor Skills, 1982; 55(2): 547-552. doi:10.2466/pms.1982.55.2.547

23.Ivashchenko O, Kapkan O, Khudolii O, Yermakova T. Informative Indicators of 14-15 Years' Age Boys' Motor Fitness. Teoriâ Ta Metodika Fìzičnogo Vihovannâ, 2017; 17(2): 86-97. doi:10.17309/tmfv.2017.2.1193

24.Ivashchenko OV, Shepelenko HP. Comparative characteristics of Coordination fitness and power of middle class.Teoriâ ta Metodika Fìzičnogo Vihovannâ, 2014: 0(2): 22-30. doi:10.17309/tmfv.2014.2.1096 (in Ukrainian)

25.Peric T. Analysis of Fitness Level of School-Age Children on the Czech Republic. Proceedings of the 10th International Conference on Kinanthropology: Sport and Quality of Life. 2016; 279-88. 


\section{Information about the authors:}

Ivashchenko O.V.; http://orcid.org/0000-0002-2708-5636; Faculty of Physical Education and Sports, H.S. Skovoroda Kharkiv National Pedagogical University; Alchevskyh str. 29, Kharkiv, 61002, Ukraine.

Khudolii O.M.; (Corresponding author); http://orcid.org/ 0000-0002-5605-9939; tmfv@tmfv.com.ua; Faculty of Physical Education and Sports, H.S. Skovoroda Kharkiv National Pedagogical University; Alchevskyh str. 29, Kharkiv, 61002, Ukraine.

lermakov S.S.; http://orcid.org/0000-0002-5039-4517; Department of Tourism and Recreation, Gdansk University of Physical Education and Sport; Kazimierza Górskiego 1, 80-336 Gdańsk, Poland.

Veremeenko V.Yu.; http://orcid.org/0000-0002-9826-9678; Faculty of Physical Education and Sports, H.S. Skovoroda Kharkiv National Pedagogical University; Alchevskyh str. 29, Kharkiv, 61002, Ukraine.

Lopatiev A.O.; http://orcid.org/0000-0002-4474-7558; Department of Shooting and Technical Sports, Lviv State University of Physical Culture, Ukraine; str. Kostiushka, 11, m. Lviv, 79007, Ukraine.

Cite this article as: Ivashchenko OV, Khudolii OM, Iermakov SS, Veremeenko VYu, Lopatiev AO. Power abilities: recognition of the level of development in girls aged 12-14 years. Pedagogics, psychology, medical-biological problems of physical training and sports, 2018;22(3):142-148. doi:10.15561/18189172.2018.0305

The electronic version of this article is the complete one and can be found online at: http://www.sportpedagogy.org.ua/index.php/PPS/issue/archive

This is an Open Access article distributed under the terms of the Creative Commons Attribution License, which permits unrestricted use, distribution, and reproduction in any medium, provided the original work is properly cited (http://creativecommons.org/licenses/by/4.0/deed.en).

Received: 18.03.2018

Accepted: 15.04.2018; Published: 30.06.2018 